BOOK REVIEW 



\section{STEVE KEEN}

\section{Debunking economics}

The world has reduced its economic growth rates since several decades ago. Besides, there have been periods of economic "moderation" and economic crisis. Prior to the crisis of 2008, the world seemed to be running properly, but suddenly things changed and mainstream economists were not able to explain the account of this crisis. There were some dissenting economists who were able to and did it and not only did so, they forecasted this crisis long time in advance, but only few listened. Perhaps the one that better explained what was about to happen

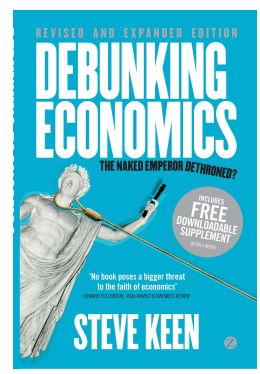
and better forecasted the crisis was Steve Keen. All what is behind the economic crisis is developed in his book Debunking Economics.

In Dr. Keen view, there is nothing more dangerous than a bad Economic Theory, since whenever Economic Policy is applied to the real world, based on this erroneous theory, the economic aftermaths of this policy have led countries to a disaster, just like it's been happening for at least thirty years so far. So the bad theory led to a bad policy and, therefore, to the economic crisis and the increase in the levels of poverty, so at the end of its way, bad economic theory produces more poverty in the world, and real people suffer and die because of it.

Debunking Economics is a profound critic to Neoclassical Economics theory. At the very beginning, the reader might think the main critic is about Microeconomic theory as he starts debunking consumer theory fallacies and concludes that the demand curve cannot be derived from this theory. One implication of this is that preferences cannot be aggregated, therefore many macroeconomics models, as well as those of international theory that depart from aggregated preferences, are false.

The theory of the firm has a similar fate: in the book it is debunked not only the neoclassical approach due to his lack of reality, but it also makes an excellent introduction of the Sraffian Economics, that perhaps, could be one of the critics that could lead the Economic to a more realistic theory of the firm. By the same token, the critic of the definition and use -and abuse- in Neoclassical Economics of the term capital is analyzed and debunked in this part. In fact, once we start thinking about the use of capital in Neoclassical Economics models, it doesn't make sense at all: perfect mobility of capital? Immediate change of capital from one industry to another? Or, as depicted in macro models, one single kind of capital to produce one single good? Does Neoclassical Economics make sense when it uses the notion of capital in this way?

It has become a mantra the phrase that states that the assumption does not matter, as long as it is useful to understand and to predict. Dr. Keen debunks that statement too, proving that such statement has been used to shield Neoclassical 
Economics when its statements seem to make no sense or look unrealistic. There is also a critic to the epistemology of Neoclassical Economics., but the best part is yet to come.

Debunking Macroeconomics takes its place in the center of the book. There is no better place for this, since it rings down the curtain to let us realize that the IS-LM analysis is nothing but the Neoclassical reading of the General Theory of Keynes. One of the amazing facts of this, is that the author of such analysis, Hicks himself, decades later would state that he is guilty or at least responsible for the misreading of the General Theory. The modern Macroeconomic models based on general equilibrium are debunked too. The main critic is that this modeling is nothing but Microeconomics applied to Macroeconomics, since the former is wrong so is the Macro modeling that uses this approach.

It would seem that there is nothing else, but the next section is about understanding the great depression and the great recession. It is also a critic of the neoclassical approach to the explanation of such events. One main argument is that, obsessed with equilibrium and stability, the neoclassical economists failed to explain those events. When those historical facts are analyzed from a different approach, it is clear the crisis was coming. But neoclassical economists are blind and deaf, and only listen to themselves.

There is also a profound critic of the financial market theory, which shares the same mistakes as those of Micro and Macro neoclassical models: they assume same preferences, the Nostradamus ability to predict markets behavior, stability and equilibria. In a world like this, crisis are not possible. Then he introduces the Minsky analysis that states that the crisis should be at least one of the possible outcomes of any economic model. When Neoclassical Economics models fail in having such outcome, they fail in predicting and explaining the reality as well.

The last part is the quest for alternatives and a critic to the Marxian economics. When coming to this chapter it is clear that the critic to Neoclassical Economics is not a political one, "is not from the left or the right, but from the logic". Nevertheless, there is a chapter that analyses Marxian Economics and another contemporary schools of economic taught. His conclusion is that we do not have any school that could oppose toe-to-toe to the neoclassical, but the understanding and developing of such schools could lead us towards a more realistic economic theory.

Dr. Keen is very critic of the economists and the Economy as a science. He never depicts himself as an economist, but he is wrong. Jostein Gaarder, in Sophia's world, states that a philosopher is someone that makes the right philosophical questions but also someone that knows the philosophical schools of at least two thousand years. Economics as a Science is not that old, but Steve knows and quotes throughout the book the main schools of economic analysis, from the Classicals to the post Keynesian and other contemporary approaches. So the book is not only a critic, it's also an immersion into several schools of economics. In Gaader words, Dr. Steve is a real economist who has the eyes opened and is not blinded by Neoclassical Economics. 
Any student or professor of Economics should read this book. It will lead them to a better understanding not only of Neoclassical Economics, but also of the real world. It also offers plenty of research ramifications that, I am pretty sure, will become a golden mine for those interested in understanding real economic world and in developing new ways of economic thinking.

Darío Ibarra Zavala

Professor at Mexican State Autonomous University, and translator into Spanish of Debunking Economics in Spanish,

darioibarra@yahoo.com 
